\title{
Adolescents and Young Adults with Chronic or End-Stage Kidney Disease
}

\author{
Maria E. Ferris ${ }^{a} \quad$ J. Alexander Miles ${ }^{b}$ Meredith L. Seamon ${ }^{c}$

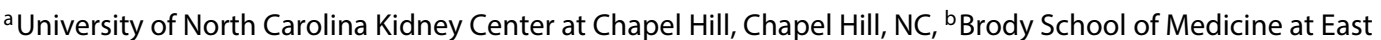 \\ Carolina University, Greenville, NC, and 'University of Utah, Department of Pediatrics, Division of Pediatric \\ Nephrology, Salt Lake City, UT, USA
}

\section{Key Words}

Chronic kidney disease - End-stage kidney disease .

Adolescent · Young adult

\begin{abstract}
Background: Adolescents and young adults face unique and complex physical, psychological, and family challenges. Despite improvements in care for chronic kidney disease (CKD) and end-stage kidney disease (ESKD), long-term mortality for children, adolescents, and young adults with CKD remains substantially higher than their healthy counterparts. Summary: In this article, we discuss the complex challenges that adolescent and young adult CKD/ESKD patients face. Adolescents have different CKD etiologies and progress along a course dissimilar to the adult population, but have similar multifarious comorbidities. In the setting of puberty and learning to become self-sufficient, adolescence is a critical time for growth and psychosocial development. Physiological complications of CKD underlie many of the longterm outcomes. CKD-mineral and bone disorder and anemia are particularly challenging given that they are exacerbated by the rapid growth of adolescents. Endocrine imbalances and malnutrition can delay and limit growth. All of these
\end{abstract}

factors, together with family dynamics and socioeconomic status, contribute to the poor long-term outcomes and decreased quality of life (QoL) for these patients and their families. Key Messages: Care for the adolescent CKD/ESKD population is uniquely challenging, but research has identified ways in which we can continue to improve long-term outcomes and QoL for adolescents with CKD/ESKD.

(c) 2016 S. Karger AG, Base

\section{Introduction}

Children, adolescents, and young adults constitute less than $5 \%$ of the end-stage kidney disease (ESKD) population and their 10-year survival ranges from 70 to $85 \%$ [ 1 , 2]. Despite these figures, their mortality rate is still 30 times higher than their healthy peers [1]. They mainly die of cardiovascular causes and infection rather than from renal failure [3]. Adolescents with CKD and ESKD experience the physical and psychological demands of puberty while having to learn to self-manage their comorbidities. In this manuscript, we will discuss some of the unique characteristics of this patient population and give the providers suggestions for their care.

\section{KARGER}

E-Mail karger@karger.com

www.karger.com/bpu
C 2016 S. Karger AG, Base

0253-5068/16/0413-0205\$39.50/0
Maria E. Ferris, MD, MPH, $\mathrm{PhD}$

7021 Burnett Womack

UNC at Chapel Hill

NC 29599-7155 (USA)

E-Mail maria_ferris@med.unc.edu 


\section{Causes of CKD}

While congenital anomalies of the kidneys and urinary tract account for $73 \%$ of ESKD patients in the $0-1$ years age group, this figure diminishes to $38.7 \%$ in the older than 12 years age group [2]. Glomerulonephritis and focal segmental glomerulosclerosis account for one-third of diagnoses in the older than 12 years age group (16.5 and $16.2 \%$, respectively) [2].

\section{Growth and Sexual Development}

CKD/ESKD affect growth due to multiple factors including metabolic acidosis, decreased caloric intake, metabolic bone disease, reduced gonadal hormone production, growth hormone resistance, and increased levels of IGF-1 binding proteins [4]. These patients often present with a delay in puberty, but its onset may lead to a faster decline in renal function [5].

\section{CKD-Mineral and Bone Disorder}

Adolescence is a crucial time for accrual of skeletal mass with approximately $25 \%$ of this mass being laid down during the 2-year period of peak height velocity [6]. Both bone mass and bone strength are known to be affected by the uremic state, and as such, adolescents with $\mathrm{CKD}$ experience changes in bone modeling/remodeling that may ultimately impact their quality of life (QoL) and long-term health. In addition, there has been increasing appreciation in the last decade of the cardiovascular calcifications that are associated with $\mathrm{CKD}$, along with the resultant increase in mortality related to cardiovascular disease for these patients $[7,8]$. As such, the triad of bone disease, disordered mineral metabolism, and cardiovascular disease in the setting of renal dysfunction, is now referred to as 'CKD-mineral and bone disorder', or CKDMBD [9]. CKD-MBD is the result of complex signaling mechanisms between the skeleton, kidneys, and parathyroid glands in the setting of renal dysfunction, which leads to alterations in serum values of calcium, phosphorus, FGF23 (a bone-derived regulator of phosphate metabolism), parathyroid hormone (PTH) and vitamin D metabolites $[7,8]$. These changes have been shown to occur early in the course of CKD with evidence of increased levels of FGF23 in patients with stage 2 CKD [7].

The clinical manifestations of CKD-MBD in the adolescent population are a source of significant mor- bidity and mortality, and include such entities as bone pain, myopathy, fractures and cardiovascular calcifications, in addition to poor growth in those with an earlier onset of CKD [6]. As such, it is imperative for providers caring for adolescents with CKD to be vigilant in monitoring biochemical parameters (calcium, phosphorus, $\mathrm{PTH}$, and alkaline phosphatase) in order to minimize these complications. Bone biopsy remains the gold standard for assessing renal bone disease; however, it is not widely used in the care of adolescents with CKD. The Kidney Disease Outcomes Quality Initiatives (KDOQI) endorses a bone biopsy for the following clinical indications: (1) pathological fractures, (2) unexplained hypercalcemia and (3) concern for aluminum toxicity [10]. Dual X-ray absorptiometry is not recommended for use in children with CKD due to its substantial limitations in this population, a position endorsed by both the National Kidney Foundation (KDOQI guidelines) and the International Society for Clinical Densitometry [11].

The management of CKD-MBD involves maintaining serum calcium and phosphorus within the normal range for age, treating $25(\mathrm{OH})$ vitamin $\mathrm{D}$ deficiency if present, and maintaining a serum PTH level appropriate for the level of CKD. In adolescents, calciumcontaining phosphate binders remain the most widely used; however, it is recommended that the total daily intake of elemental calcium, from both the diet and phosphate binders, not surpass $2.5 \mathrm{~g}$ per day in order to minimize the risk for cardiovascular calcifications [12]. Thus, a calcium-free phosphate binder may be useful in the adolescent with persistent hypercalcemia, as well as correcting metabolic acidosis in pediatric patients [13, 14].

The treatment of $25(\mathrm{OH})$ vitamin $\mathrm{D}$ deficiency in children and adolescents with CKD delays the onset of secondary hyperparathyroidism $[13,15]$. Thus, guidelines endorse treatment of $25(\mathrm{OH})$ vitamin D deficiency/insufficiency in the setting of an elevated PTH with ergocalciferol/cholecalciferol first. In regard to active vitamin D analogs, a 2010 Cochrane review showed a similar decrease in PTH levels with all preparations studied $[13,16]$. However, oversuppression of PTH levels with active vitamin $\mathrm{D}$ sterols is associated with a dynamic bone disease with resultant growth failure in younger children and teens [13]. Currently, the calcimimetic agent, cinacalcet, is not approved for use in children under the age of 18 years. However, pediatric randomized controlled trials are underway, which may provide important data that would allow their use in the 
younger adolescent population, which would likely decrease the need for subtotal parathyroidectomy in this population.

\section{Anemia}

Anemia is a frequent complication of CKD with increasing prevalence as this condition progresses, thereby affecting nearly all patients on dialysis. The etiology of anemia in the adolescent population with CKD is often multifactorial. While in women menstruation alterations play an important role, erythropoietin deficiency remains the principal cause. Other important contributors include blood loss, iron deficiency, vitamin deficiency/poor nutrition, inflammation, poorly controlled hyperparathyroidism, medications (e.g., angiotensin converting enzyme inhibitors and angiotensin receptor blockers), inadequate dialysis, and systemic disease $[17,18]$.

The systemic effects of anemia in the adolescent age group are considerable, including fatigue, depression, sleep disturbance, impaired cognitive function, loss of appetite and decreased exercise tolerance, ultimately resulting in poor QoL [17]. In addition, anemia has a significant impact on overall health outcomes given its association with cardiovascular complications, such as left ventricular hypertrophy, blood transfusions resulting in human leukocyte antigen sensitization and potential decreased probability of renal transplantation, and increased mortality [18].

Given these substantial effects on the long-term health of the adolescents with CKD, as well as on their QoL, providers should monitor for the development of anemia and iron deficiency in this population. The threshold to diagnose anemia in children with CKD is age dependent, but approaches the KDOQI standard for adult females of $<12 \mathrm{~g} / \mathrm{dl}$ for children age of $12-15$ years [9]. Iron studies should be obtained in all adolescents with CKD, regardless of use of an erythropoietin stimulating agent (ESA), with a goal transferrin saturation $>20 \%$ and serum ferritin level $>100 \mathrm{ng} / \mathrm{ml}$, though the utility of the serum ferritin level as a measure of iron status has been questioned based on recent studies, as it is thought to be more reflective of the inflammatory state [13]. The preferred initial route of administration for iron is by mouth, except in those who are on maintenance hemodialysis [10].

The timing of ESA initiation should take into account benefits such as better QoL, improved school attendance and performance, and averting transfusions. It is recom- mended that ESA initiation occur in pediatric patients with hemoglobin of 9-10 g/dl, with a target range of 11$13 \mathrm{~g} / \mathrm{dl}$ [17].

\section{Hypertension}

Hypertension is the most common complication of $\mathrm{CKD} / \mathrm{ESKD}$ as it affects up to $80 \%$ of children and adolescents with this condition. It is thought to derive from volume expansion, excess renin or iatrogenic (corticosteroids, cyclosporine, tacrolimus) causes. Anemia, CKDMBD, chronic inflammation, oxidant stress, and dyslipidemia increase the risk for poor cardiovascular outcomes [19]. Aggressive control of blood pressure (based on normal age ranges), lipid metabolism, and anemia is critical in these patients. Control of anemia and hypertension will improve neuro-cognition and school performance.

\section{Other Comorbidities of CKD}

Endocrine dysfunction in adolescents with $\mathrm{CKD} /$ ESKD often presents as 'sick euthyroid syndrome' (low total and free T4 and T3, but normal thyroid-stimulating hormone, and normal or decreased thyrotropin releasing hormone) and gonadal hormone abnormalities. Males and females both have increased luteinizing hormone and follicle stimulating hormone levels. Men have less testosterone and adrenal androgens while women have less estrogen and loss of luteinizing hormone pulsatile pattern [20]. There is little information regarding pregnancy.

Difficulty with nutrition and nutrient utilization leads to uremic malnutrition. Uremia presents with a constellation of signs and symptoms, characterized by anorexia, nausea, vomiting, growth retardation, peripheral neuropathy, and CNS abnormalities (cognitive impairment, loss of concentration, lethargy, seizures, coma or death) [21]. Uremic patients also have a risk for bleeding secondary to abnormal platelet adhesion and aggregation properties [20].

\section{Psychosocial Aspects of CKD}

Similar to other adolescents with a chronic health condition, those with CKD/ESKD face challenges to their psychosocial well-being including altered body image due to medication effects (i.e., steroids or cyclosporine) or procedures (i.e., dialysis access), as well as absence from normal age-appropriate activities (i.e., school). Children and adolescents with CKD have considerably lower health-related QoL compared to their healthy peers in four important 
domains including physical, school, emotional, and social [22]. Surprisingly, those patients who were older and had a longer duration of disease had higher scores in the physical, emotional, and social functioning domains [22]. However, the older patients had lower scores in the school domain, which may be related to impaired neurocognitive function [17]. Interestingly, in another study, dialysis patients scored equally, or higher, than their transplant counterparts in all QoL domains [23].

In addition to altered QoL, adolescents with $\mathrm{CKD} /$ ESKD are at higher risk for depression compared to their healthy peers. In a study by Kogon et al. [24], 30\% of the study patients, age 9-18 years with CKD stages $3-5$, met criteria for depression, compared to the reported rate of $0.4-8.3 \%$ in the general child and adolescent population. Depression was more common in those over the age of 13 (34\%) compared to $18 \%$ in those under the age of 13 years [24]. Given the prevalence of depression in the adolescent $\mathrm{CKD} / \mathrm{ESKD}$ population, and its potential impact on other aspects of care (i.e., adherence), providers should be routinely screening patients for depressive symptoms.

Once a diagnosis of depression is made, appropriate therapeutic interventions must be instituted. Data from the adult literature suggest that depression in patients with CKD/ESKD is undertreated and medications underutilized [25]. This may be related to the exclusion of patients with CKD/ESKD from pharmacologic trials due to safety concerns. Until data from RCTs are available in this population, if a trial of medication is considered, selective serotonin reuptake inhibitors are the preferred medication class [25]. In addition to pharmacologic treatment, another treatment option for depression, which has been studied in the adult CKD population, is cognitive behavioral therapy. Data show that cognitive behavioral therapy is effective in reducing CKD patients' scores on a widely-used depression screen [26].

\section{Family Aspects of Adolescent CKD}

The burden of care for adolescents with CKD is substantial, and while adolescents are learning to take more responsibility for their care, parents and other caregivers are still primarily responsible for supervision and delivery of this care. One example includes the number of medications needed by adolescents with CKD. Using the Chronic Kidney Disease in Children cohort, it was demonstrated that the number of medications needed for CKD-related comorbidities increased with CKD stage (2.5-fold for stage 4 vs. stage 2) [27]. Interestingly, medication non-

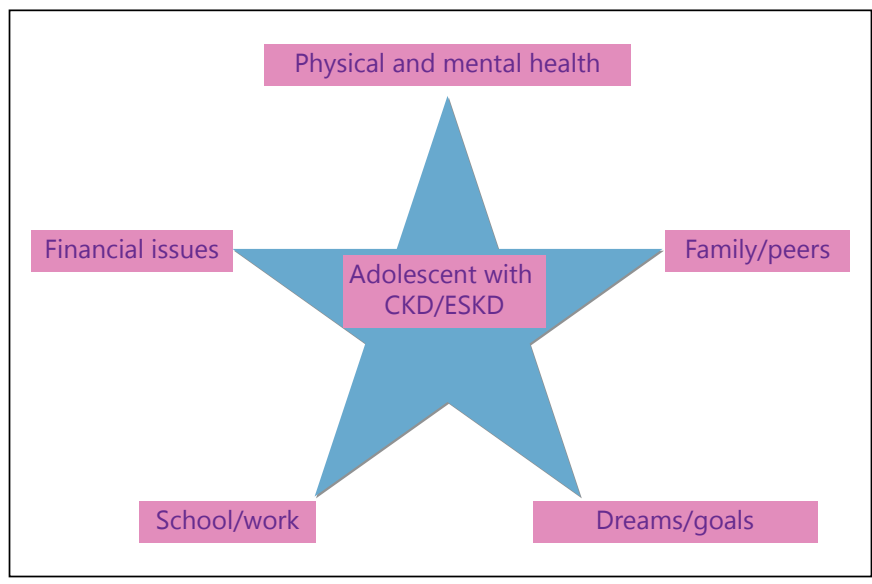

Fig. 1. Competing interests in adolescents with CKD/ESKD. Patients are represented as stars as we honor their resilience.

adherence in this study population was associated with increased medication dosing frequency (more than 2 times per day) rather than the number of medications. In addition to medication administration, caregivers assist with diet and fluid restrictions, blood pressure measurements, injections (ESAs, growth hormone), and dialysis (peritoneal dialysis or home hemodialysis) [17].

As such, it is not surprising that caregivers of youth with CKD have higher levels of psychological distress as well as decreased QoL [28]. Lower socioeconomic status was also associated with reduced QoL for caretakers [29]. Medway et al. [28] recently explored the financial stress of caring for a child with CKD in an in-depth qualitative study. Parents in this study prioritized their child's care, and as such, many were unable to maintain employment. In addition, many of these caregivers experienced difficulty in accessing government support, which further contributed to financial stress. Many families were not aware of options available to alleviate 'caregiver burnout' and some of the financial burden, including respite care. Use of a multidisciplinary care team, including child life specialists and social workers, would be helpful for addressing these important needs of adolescent patients and their caregivers.

\section{Healthcare Transition, Self-Management and Adherence}

Adolescents and young adults with CKD/ESKD must learn to manage their health in order to achieve good outcomes and longer survival, particularly when their par- 
ents stop managing their condition. This can be achieved through a customized healthcare transition preparation at both the pediatric and adult-focused healthcare settings, considering the patient/family's culture and literacy level. Healthcare transition readiness should be measured to monitor progress and make adjustments as needed, based on the level of cognition. For those with moderate to severe cognitive impairment, this preparation may only be focused on setting up a power of attorney document and future living arrangements (i.e. group homes).

There are a few published tools to measure transition readiness in patients with $\mathrm{CKD} / \mathrm{ESKD}$ who speak English or Spanish [30-33]. Early data show that patients who are women, older in age, Caucasians, or who have greater literacy skills or private insurance appear to have greater transition readiness [31-33], but further validation is underway.

Adherence in adolescents and young adults with CKD/ ESKD is an area of concern for all those involved (pa- tients, parents, health providers). But, adherence has been an elusive concept to study as an agreed upon definition is yet to occur. Patients with a renal transplant have less room for error than those with CKD. Transplant patients should be encouraged to take their medications at a $95 \%$ rate or have immunosuppressive levels that range less than 2 standard deviations. Interventions such as text messaging or interactive patient education platforms are being tested in clinical trials.

Adherence to medical treatment may take second place in the adolescents' minds as they have other competing interests such the need to be like their peers, financial issues, school/work, goals and dreams (fig. 1). In this figure, we represent the adolescent patient as a star, because in our opinion, these patients deserve our respect and understanding while honoring their resilience and ability to cope with such a devastating diagnosis. This resilience may explain their greater reported QoL compared to what their parents report as proxy in several studies.

\section{References}

1 Ferris ME, Gipson DS, Kimmel PL, Eggers PW: Trends in treatment and outcomes of survival of adolescents initiating end-stage renal disease care in the United States of America. Pediatr Nephrol 2006;21:1020-1026.

2 Saran R, Li Y, Robinson B, et al: US Renal Data System 2014 annual data report: epidemiology of kidney disease in the United States. Am J Kidney Dis 2015;66(1 suppl 1):Svii, S1-S305.

3 Harambat J, van Stralen KG, Kim JJ, Tizard EJ: Epidemiology of chronic kidney disease in children. Pediatr Nephrol 2012;27:363-373.

4 Hardy R, Kuh D, Whincup PH, Wadsworth ME: Age at puberty and adult blood pressure and body size in a British birth cohort study. J Hypertens 2006;24:59-66.

5 Ardissino G, Testa S, Daccò V, Paglialonga F, Viganò S, Felice-Civitillo C, Battaglino F, Bettinelli A, Bordugo A, Cecchetti V, De Pascale S, La Manna A, Li Volti S, Maringhini S, Montini G, Pennesi M, Peratoner L: Puberty is associated with increased deterioration of renal function in patients with CKD: data from the ItalKid project. Arch Dis Child 2012;97:885-888.

6 Schmitt CP, Mehls O: Disorders of bone mineral metabolism in chronic kidney disease; in Geary DE, Schaefer F (eds): Comprehensive Pediatric Nephrology. Mosby Elsevier, 2008.

7 Wesseling-Perry K, Salusky IB: Chronic kidney disease: mineral and bone disorder in children. Semin Nephrol 2013;33:169-179.

8 Wesseling K, Bakkaloglu S, Salusky I: Chronic kidney disease mineral and bone disorder in children. Pediatr Nephrol 2008;23:195207.
9 Kidney Disease: Improving Global Outcomes (KDIGO) CKD-MBD Work Group: KDIGO clinical practice guideline for the diagnosis, evaluation, prevention, and treatment of chronic kidney disease-mineral and bone disorder (CKD-MBD). Kidney Int 2009;76(suppl 113):S1-S130.

10 National Kidney Foundation: KDOQI clinical practice guidelines for bone metabolism and disease in children with chronic kidney disease. Am J Kidney Dis 2005;46:S1-S121.

11 Weber LT, Mehls O: Limitations of dual X-ray absorptiometry in children with chronic kidney disease. Pediatr Nephrol 2010;25:3-5.

12 Wesseling-Perry K, Salusky I: Phosphate binders, vitamin $\mathrm{D}$, and calcimimetics in the management of chronic kidney disease-mineral bone disorders (CKD-MBD) in children. Pediatr Nephrol 2013;28:617-625.

13 Bacchetta J, Harambat J, Cochat P, Salusky IB, Wesseling-Perry K: The consequences of chronic kidney disease on bone metabolism and growth in children. Nephrol Dial Transplant 2012;27:3063-3071.

14 Gonzalez E, Schomberg J, Amin N, et al: Sevelamer carbonate increases serum bicarbonate in pediatric dialysis patients. Pediatr Nephrol 2010;25:373-375.

15 Shroff R, Wan M, Gullett A, et al: Ergocalciferol supplementation in children with CKD delays the onset of secondary hyperparathyroidism: a randomized trial. Clin J Am Soc Nephrol 2012;7:216-223.

16 Geary DF, Hodson EM, Craig JC: Interventions for bone disease in children with chron- ic kidney disease. Cochrane Database Syst Rev 2010;1:CD008327.

17 Massengill SF, Ferris M: Chronic kidney disease in children and adolescents. Pediatr Rev 2014;35:16-29.

18 Warady BA, Neu AM, Schaefer F: Optimal care of the infant, child, and adolescent on dialysis: 2014 update. Am J Kidney Dis 2014;64: 128-142.

19 Shroff R, Weaver DJ Jr, Mitsnefes MM: Cardiovascular complications in children with chronic kidney disease. Nat Rev Nephrol 2011;7:642-649.

20 Sinha R, Marks SD: Pediatric chronic kidney disease; in Wilcox D, Godbole C, Cooper C (eds): Pediatric Urology Book, 2012.

21 Gerson AC, Butler R, Moxey-Mims M, Wentz A, Shinnar S, Lande MB, Mendley SR, Warady BA, Furth SL, Hooper SR: Neurocognitive outcomes in children with chronic kidney disease: current findings and contemporary endeavors. Ment Retard Dev Disabil Res Rev 2006;12:208-215.

22 Gerson AC, Wentz A, Abraham AG, Mendley SR, Hooper SR, Butler RW, Gipson DS, Lande MB, Shinnar S, Moxey-Mims MM, Warady BA, Furth SL: Health-related quality of life of children with mild to moderate chronic kidney disease. Pediatrics 2010;125: e349-e357.

23 McKenna AM, Keating LE, Vigneux A, Stevens S, Williams A, Geary DF: Quality of life in children with chronic kidney disease - patient and caregiver assessments. Nephrol Dial Transplant 2006;21:1899-1905. 
24 Kogon AJ, Vander Stoep A, Weiss NS, Smith J, Flynn JT, McCauley E: Depression and its associated factors in pediatric chronic kidney disease. Pediatr Nephrol 2013;28:1855-1861.

25 Hedayati SS, Yalamanchili V, Finkelstein FO: A practical approach to the treatment of depression in patients with chronic kidney disease and end-stage renal disease. Kidney Int 2012;81:247-255.

26 Duarte PS, Miyazaki MC, Blay SL, et al: Cognitive-behavioral group therapy is an effective treatment for major depression in hemodialysis patients. Kidney Int 2009;76:414-421.

27 Blydt-Hansen TD, Pierce CB, Cai Y, Samsonov D, Massengill S, Moxey-Mims M, Furth SL: Medication treatment complexity and adherence in children with CKD. CJASN 2014;9:247-254.
28 Medway M, Tong A, Craig JC, Kim S, Mackie F, McTaggart S, Walker A, Wong G: Parental perspectives on the financial impact of caring for a child with CKD. Am J Kid Dis 2015;65: 384-393.

29 Tsai TC, Liu SI, Tsai JD, Chou LH: Psychosocial effects on caregivers for children on chronic peritoneal dialysis. Kidney Int 2006; 70:1983-1987.

30 Ferris ME, Harward DH, Bickford K, Layton JB, Ferris MT, Hogan SL, Gipson DS, McCoy LP, Hooper SR: A clinical tool to measure the components of health-care transition from pediatric care to adult care: the UNC TR(x) ANSITION scale. Ren Fail 2012;34:744-753.

31 Cantú-Quintanilla G, Ferris M, Otero A, Gutiérrez-Almaraz A, Valverde-Rosas S, Velázquez-Jones L, Luque-Coqui $\mathrm{M}$, Cohen S, Medeiros M: Validation of the UNC

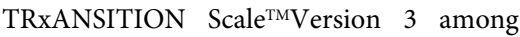
Mexican adolescents with chronic kidney disease. J Pediatr Nurs 2015;30:e71-e81.
32 Ferris M, Cohen S, Haberman C, Javalkar K, Massengill S, Mahan JD, Kim S, Bickford K, Cantu G, Medeiros M, Phillips A, Ferris MT, Hooper SR: Self-management and transition-readiness assessment: development, reliability, and factor structure of the STARx Questionnaire. J Pediatr Nurs 2015;30:691699.

33 Cohen SE, Hooper SR, Javalkar K, Haberman C, Fenton N, Lai H, Mahan JD, Massengill S, Kelly M, Cantú G, Medeiros M, Phillips A, Sawicki G, Wood D, Johnson M, Benton $\mathrm{MH}$, Ferris M: Self-management and transition readiness assessment: concurrent, predictive and discriminant validation of the STARx questionnaire. J Pediatr Nurs 2015;30:668676 